\title{
Reactivation of Klingnau reservoir sidearm: Numerical simulation of sediment release downstream
}

\author{
A. Amini \& P. Heller \\ e-dric.ch Ltd., Switzerland \\ G. De Cesare \& A.J. Schleiss \\ Ecole Polytechnique Fédérale de Lausanne (EPFL), Switzerland \\ N. Kräuchi \& P. Rötheli \\ Department of Landscape and Waters, Canton of Aargau, Switzerland
}

\begin{abstract}
The Klingnau reservoir, situated in north Switzerland, suffers from sedimentation in its left enlargement. The dam is placed in the Aare River about $1 \mathrm{~km}$ upstream of its confluence with the Rhine. Due to natural conservation and flood protection reasons, it has been sought for decades to slowdown the sedimentation process in the reservoir. For this purpose, $20^{\prime} 000 \mathrm{~m}^{3}$ of deposited material will be excavated by suction dredge and injected downstream into the Rhine. The objective of the present study is firstly to spot the best place for the material injection downstream. It is then aimed to assure that this injected material will not deposit along the Rhine River down to the Birsfelden dam. The latter is situated $60 \mathrm{~km}$ downstream of Klingnau and is the last reservoir on the Rhine River in Swiss territory. To accurately simulate the sedimentation process, one and two-dimensional numerical models are applied. It is confirmed that the majority of injected material stays in suspension and can be transported through the Rhine River down to Birsfelden.
\end{abstract}

\section{INTRODUCTION}

The left enlargement of the Klingnau reservoir has suffered from sedimentation for decades (Fig. 1). The deceleration of the siltation process of the Klingnau reservoir has been investigated in last years. The division of territories and water bodies of the department for constructions, traffic and environment of the Aargau canton in Switzerland plans to excavate a lateral flow canal of $2 \mathrm{~m}$ deep and $25 \mathrm{~m}$ wide and inject $20,000 \mathrm{~m}^{3}$ of the removed sediments into the rivers downstream.

The main objectives of the sidearm reactivation are the conservation of open water area, the deceleration of siltation by enhancing flow dynamics, the increase of discharge capacities and an improvement of flood supply for shorebirds in this natural reserve of international importance (Ramsar Site $N^{\circ} 507$ Klingnau reservoir).

The main aim of the present study is on one hand to optimize the sediment injection procedure and on the other hand to investigate the effect of the sediment injection downstream. The results of this study represent an essential basis for decision making in the project execution.

This study deals with suspended load transport problem as the deposited material consists mostly of very fine sand. The literature abounds with relations for predicting suspended sediment transport. Garcia \& Parker (1991) compared some of these relationships against a common set of experimental data for which direct measurements of near-bed concentration are available. Maclean (1991) calculated the net transport of suspended sediment by integrating the product of the sediment concentration and velocity over the water depth.

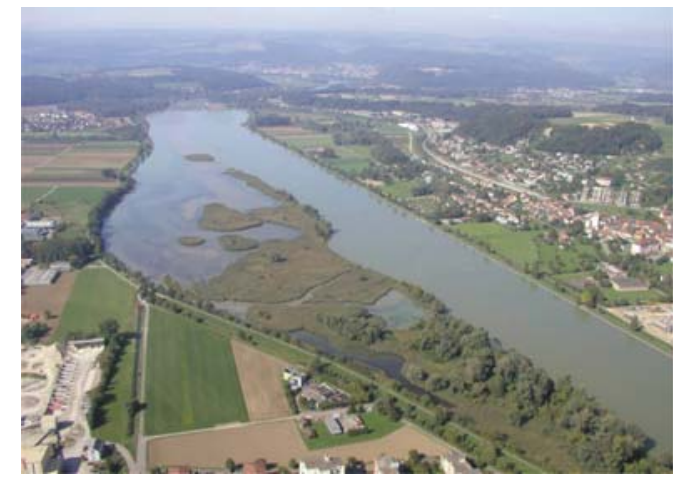

Figure 1. Sedimentation in left enlargement of Klingnau reservoir (metron, 2010). 


\section{PROJECT AREA AND SPECIFICATIONS}

The Klingnau Dam is situated about $1 \mathrm{~km}$ upstream of the Rhine-Aare junction in the Aare River in the Aargau canton in Switzerland.

\subsection{General data}

The project area covers over $60 \mathrm{~km}$ of the Rhine River upstream of the Swiss-German border. The Rhine River comprises seven dams in cascade along this distance as shown in Figure 2. All the seven reservoirs are subject to sediment transport simulations. However, a more detailed study is carried out for the most upstream Albbruck-Dogern (RADAG) reservoir.

\subsection{Hydraulic and sediment injection data}

Hourly flow data over 20 years (1993-2012) are available in three hydrodynamic stations: upstream of the Klingau dam in the Aare River, upstream of the Aare-Rhine junction in the Rhine River and far downstream in the Rhine River (Rheinfelden). A statistical analysis of these data allows establishing the project hydrology. Figure 4 illustrates the flow duration curves at the Rheinfelden station.

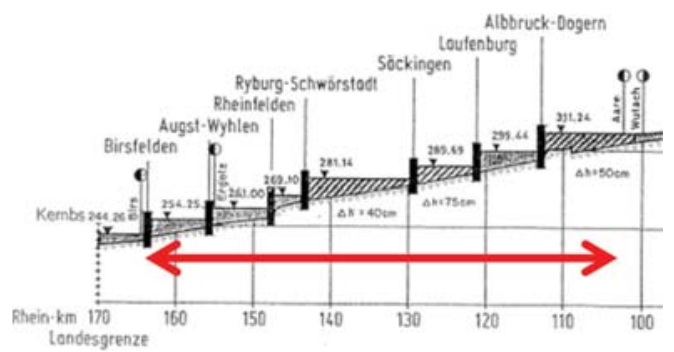

Figure 2. Longitudinal profile of the Rhine River from its junction with the Aare River down to Birsfelden dam, including seven dams in cascade.

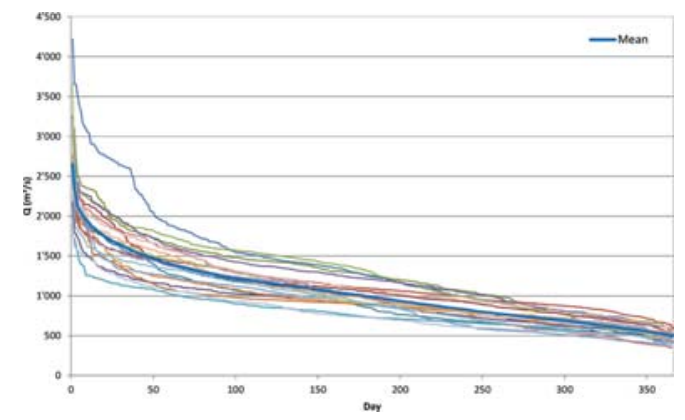

Figure 3. Flow duration curves of the Rhine River in Rheinfelden (1993-2012).

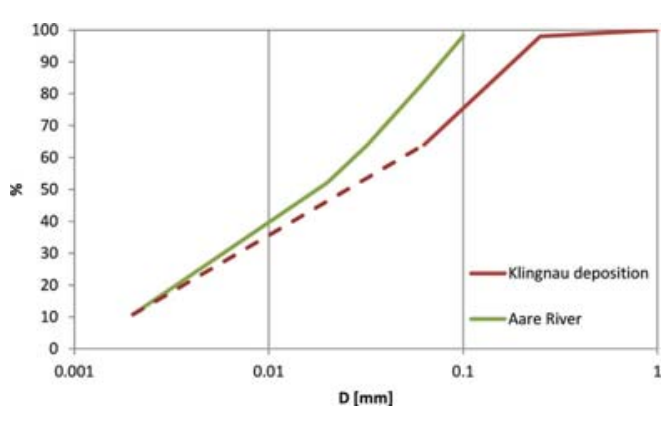

Figure 4. Gradation curve of deposited material in the Klingnau reservoir (metron, 2013) and of suspended load of the Aare river.

In the present study water discharges, $\mathrm{Q}_{\mathrm{w}}$, between 880 and $1^{\prime} 50 \mathrm{~m}^{3} / \mathrm{s}$ are simulated.

The Rhine and Aare inflows represent 0.55 and 0.45 of total inflow respectively.

The foreseen injection of solid discharge, $\mathrm{Q}_{\mathrm{s}}$, is $60 \mathrm{~m}^{3} / \mathrm{s}$ and injection can be executed 10 hours per day. This leads to a period of 33 days for injection of total volume of $20^{\prime} 000 \mathrm{~m}^{3}$ of formerly excavated sediments.

\subsection{Sediment data}

Gradation curves of deposited sediment in the Klingnau reservoir and suspended load of the Aare River are presented in Figure 4. The deposited material consists of $64 \%$ silt and clay and 34\% fine sand.

The roughness coefficient, $K_{s}$, is calculated as a function of $d_{90}$ of the river bed using the Strickler equation:

$K_{s}=\frac{21.6}{\sqrt[6]{d_{90}}}$

and is equal to $35 \mathrm{~m}^{1 / 3} / \mathrm{s}$.

The natural suspended load concentration in the Aare River is usually less than $30 \mathrm{mg} / \mathrm{l}$. However, it can rise up to $200 \mathrm{mg} / \mathrm{l}$ in case of a flood event (metron, 2010).

\section{TWO-DIMENSIONAL MODEL}

The main aim of detailed two-dimensional (2D) simulations is firstly to optimize the injection location and secondly to estimate the suspended load transport or deposition in the RADAG reservoir, the most upstream reservoir in the Rhine and consequently the most vulnerable one.

Both hydraulic and suspended load transport simulations are carried using BASEMENT model (version 2.3, R1344). BASMENT includes a 2D 
advection-diffusion module for suspended sediment transport. The hydraulic model allows computing the velocity magnitudes, shear stress and shearing velocities in the bed level. The sediment transport model is used to study the bed elevation changes during sediment injection as well as sediment concentrations, and deposited and transported sediment volumes. Figure 5 illustrates the 2D model extension including $10 \mathrm{~km}$ of the Rhine River, slightly upstream of the Aare junction down to the RADAG dam and powerhouse as well as the Leibstadt weir.

\subsection{Geometry and discharges}

The model geometry is prepared by the program SMS as it is shown in Figure 6. The Rhine River is diverted in the Werkkanal at the Leibstadt weir. The normal water elevation at the Leibstadt weir is $311.24 \mathrm{~m}$ asl for the discharges up to $1^{\prime} 800 \mathrm{~m}^{3} / \mathrm{s}$. The ecological flow at the Leibstadt weir is 300 $\mathrm{m}^{3} / \mathrm{s}$ (used also for hydropower generation) while the maximum capacity of RADAG dam and powerhouse is $1^{\prime} 100 \mathrm{~m}^{3} / \mathrm{s}$.

\subsection{Injection point optimization}

The location of sediment injection is evaluated using the hydraulic results for steady flow with a discharge

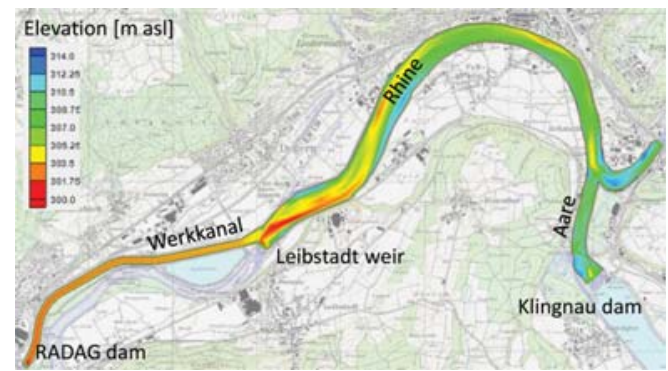

Figure 5. 2D model of RADAG reservoir.

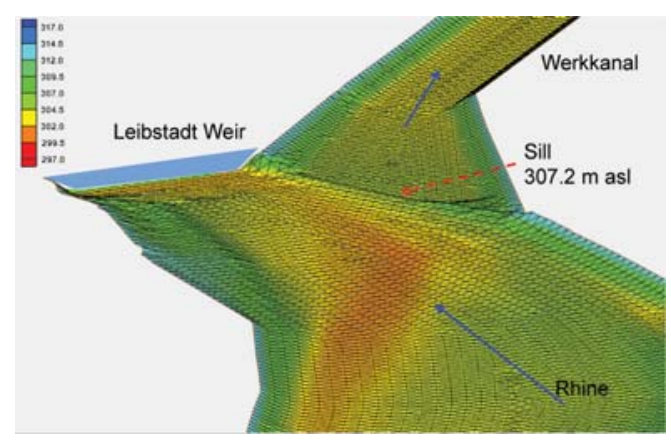

Figure 6. 2D model of the Leibstadt weir and Werkkanal entrance. of $880 \mathrm{~m}^{3} / \mathrm{s}$. Three alternatives for injection location with high velocities and turbulences are considered.

1. In the Aare, about $400 \mathrm{~m}$ downstream of the Klingnau dam,

2. In the Aare just at the Aare-Rhine junction,

3. In the Rhine, just after the junction on the left bank.

These alternatives are shown in Figure 7. The results are presented in Figure 8. The first alternative is not favorable as the discharges are low in the Aare and the major part of injected material will settle down in this river before reaching the Rhine. The second and third alternatives are quite similar in deposited volume and extension. Finally, due to practical constrains the second alternative is chosen.

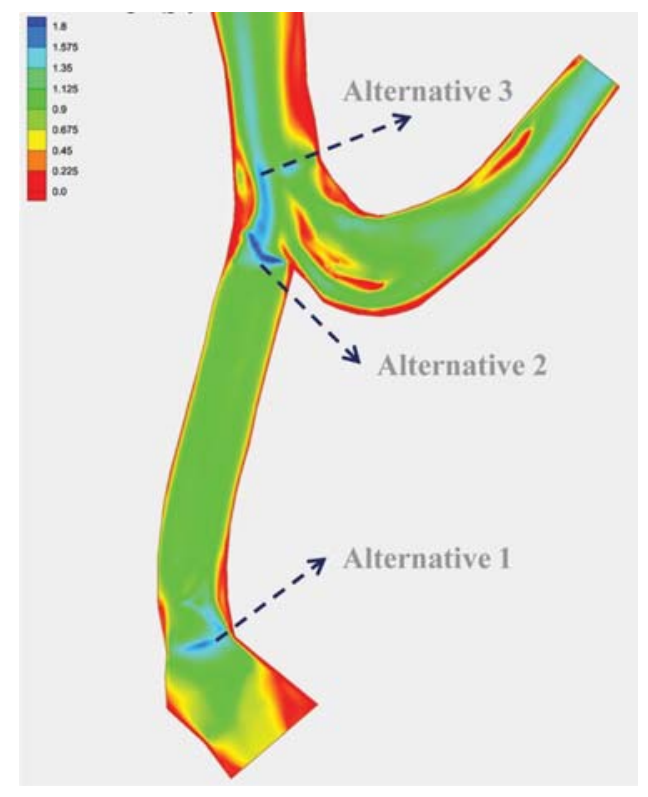

Figure 7. Velocity field for a total discharge $\mathrm{Q}_{\mathrm{w}}$ of $880 \mathrm{~m}^{3} / \mathrm{s}$ and alternatives of injection points.

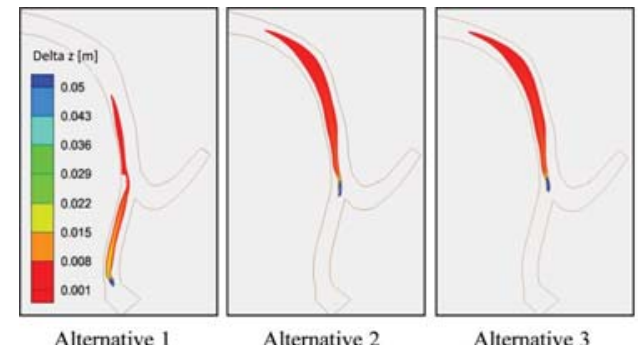

Figure 8. Deposition after 10 hours of injection with $\mathrm{Q}_{\mathrm{w}}=880 \mathrm{~m}^{3} / \mathrm{s}$ for different alternatives. 


\subsection{Sedimentation in RADAG}

RADAG is the first reservoir to be affected by the injection. The grains that cannot be transported by water as suspended load will settle down in this reservoir. That's why RADAG is studied in details with a two-dimensional model.

\subsubsection{Scenarios and boundary condition}

To ensure sediment transport during injection, steady state simulations with different discharges between 880 and 1'500 $\mathrm{m}^{3} / \mathrm{s}$ are examined. Upstream, two separated inflows of the Rhine and the Aare rivers are considered. Downstream, a fixed water elevation is considered at the Leibstadt weir. At the Leibstadt weir, a flow boundary corresponding to the ecological discharge is defined. The rest of the discharge flows through the Werkkanal.

Coupled sediment transport simulations are carried out for the minimum and maximum discharges.

\subsubsection{Shear stress}

Figure 9 compares the bed-level shear velocities with critical velocities for settlement and entrainment of grains with different diameters. The critical shear velocity is calculated by the Van Rijn relationship (Van Rijn, 1984) for initiation of suspended sediment settlement or entrainment. For each grain size a range of shear velocities is presented. The upper line is the critical shear velocity for the entrainment where the lower line represents the critical shear velocity for settling. The shear velocities for each simulated discharge are extracted in the center line of the river.

The shear velocities reduce close to the Leibstadt weir. However, they are much more significant in the Werkkanal. As such no deposition is expected in the Werkkanal. The comparison between critical shear velocities and the obtained ones from

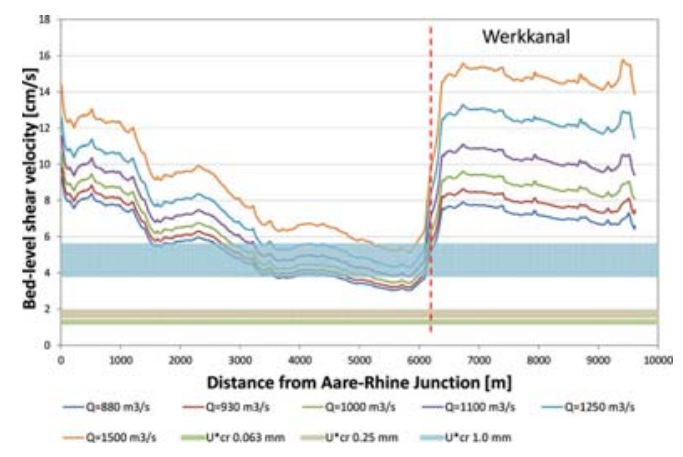

Figure 9. Bed-level shear velocities for different scenarios comparing to the critical shear velocity of grains with different sizes. simulations shows that the grains with diameter of $0.063 \mathrm{~mm}$ and $0.25 \mathrm{~mm}$ will not deposit in the reservoir. However, the grains with a diameter of $1 \mathrm{~mm}$ or more will accumulate upstream of the Leibstadt weir.

\subsubsection{Coupled model results}

The computation time for the coupled 2D sediment model over the whole injection time is very long. Therefore only two discharge (min and max) scenarios are simulated. The results are compared after 48 hours in Figure 10, where injection is performed 10 hours per day. The maximum bed level change is in the same order of magnitude for both discharges. The deposition zone extension is also very similar for both discharges and does not seem sensitive to this change. The deposited volumes after 10 hours of injection are presented in Table 1.

Figure 11 illustrates the bed level changes at the end of injection execution for a water discharge of $880 \mathrm{~m}^{3} / \mathrm{s}$. The maximum suspended load aggregation of about $50 \mathrm{~cm}$ occurs at the junction, where a kind of eddy is formed in the Aare entrance to the Rhine.

The model also reveals the evolution of suspended sediment concentration in the river during injections. It takes about two hours for the

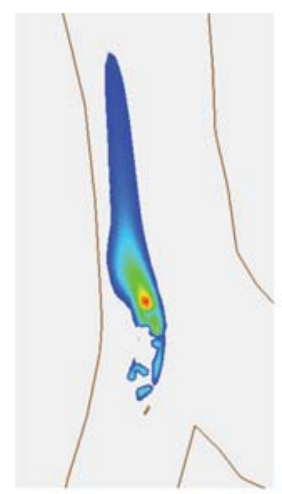

$\mathrm{Q}=880 \mathrm{~m}^{3} / \mathrm{s}$

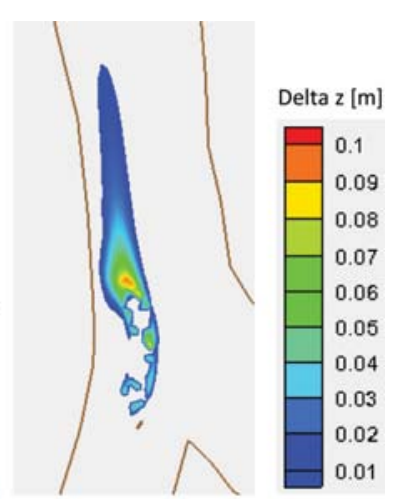

$Q=1250 \mathrm{~m}^{3} / \mathrm{s}$
Figure 10. Deposition downstream of the injection point after 2 days ( 10 hours of injection and 14 hours of pause every day) for different discharges.

Table 1. Deposition volume in the RADAG reservoir after 10 hours of injection (total injection volume of $600 \mathrm{~m}^{3}$ ).

\begin{tabular}{rll}
\hline $\begin{array}{l}\text { Discharge } \\
{\left[\mathrm{m}^{3} / \mathrm{s}\right]}\end{array}$ & $\begin{array}{l}\text { Deposition } \\
\text { volume }\left[\mathrm{m}^{3}\right]\end{array}$ & $\begin{array}{l}\text { Deposition } \\
{[\%]}\end{array}$ \\
\hline 880 & 220 & 37 \\
$1 ' 250$ & 200 & 33 \\
\hline
\end{tabular}




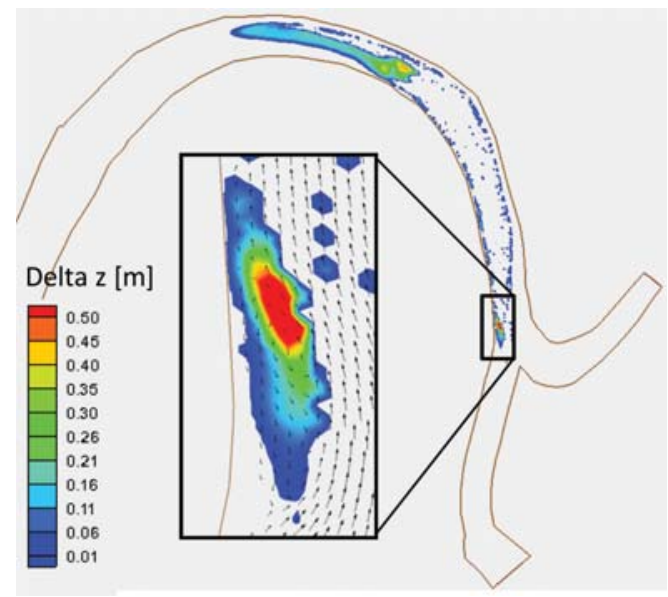

Figure 11. Deposition in the upper part of the RADAG reservoir after 33 days of injection with a discharge of $880 \mathrm{~m}^{3} / \mathrm{s}$.

suspended load to reach the Leibstadt weir and then another hour to get to the RADAG dam and powerhouse. By stopping the injection, water becomes clear again after four hours.

\subsubsection{Effect of river's natural suspended load}

To evaluate the effect of the river's natural load on injected load transport, some simulations have been carried out with the natural suspended sediment load in the Aare and the Rhine. The results does not show any significant difference compared to clear water inflow simulations.

\section{1D NUMERICAL MODEL}

\subsection{Sedimentation in the Rhine}

The 1D model aims to build a general model of the entire Rhine river reservoirs in Aargau Canton and to analyze the sediment transport over $60 \mathrm{~km}$ of the Rhine River. Hydraulic and sediment transport simulations are carried out separately for each reservoir. The sediment outflow of one model is used as the input mass in the next reservoir downstream. The gradation curve is also modified as a function of deposited mass, assuming that the bigger is the grain size the faster it settles down.

The well-known HEC-RAS model is used to perform both hydraulic and sediment transport analysis. The hydraulic simulations result in shear stress and consequently shear velocities that can be used to estimate transportation or deposition of material.

Comparing the obtained results from $1 \mathrm{D}$ and $2 \mathrm{D}$ models in the RADAG reservoir allows the validation of 1D result over 6 other reservoirs.
The obtained shear velocities in 1D model for the RADAG are slightly less than those of 2D model. The reason is that in $2 \mathrm{D}$ simulations the shear velocity is extracted from the river's center line, while in 1D model an average value is given for each section.

The percentage of transported material comparing to the initial injected material is reported in Table 2. i.g. for a discharge of $880 \mathrm{~m}^{3} / \mathrm{s}, 68 \%$ of the material is transported through RADAG into the next reservoir (Laufenburg). In Laufenburg $8 \%$ of material is deposited and only $60 \%$ of the total mass is transported to Säckingen.

The results for RADAG for a discharge of $880 \mathrm{~m}^{3} / \mathrm{s}$ are similar to those obtained from 2D model. However, for a discharge of $1 ’ 250 \mathrm{~m}^{3} / \mathrm{s}$, the 1D model gives less deposition in RADAG than the $2 \mathrm{D}$ model.

It can be conluded that with a discharge of $880 \mathrm{~m}^{3} / \mathrm{s}$ in the Rhine, $58 \%$ of the injected material will deposit along $60 \mathrm{~km}$ of the Rhine. This amount will reduce to $44 \%$ if injection is performed with a discharge of $1250 \mathrm{~m}^{3} / \mathrm{s}$ in the Rhine.

\subsection{Dry year}

In a dry year, it is possible that the discharge in the Rhine does not reach the minimum authorized discharge of $880 \mathrm{~m}^{3} / \mathrm{s}$. To evaluate such an extreme situation of injection during a dry year 1D simulation is carried out. The year 2003 is considered as the driest during the period of 1993 to 2012 . The simulation starts on August 29th and injection continues for 33 days until September 30th. It continues then with 14 days of flood. The peak discharge corresponds to the mean annual flood, i.e. $2^{\prime} 700 \mathrm{~m}^{3} / \mathrm{s}$. The natural load of Rhine and Aare rivers is included.

The simulated hydrograph and deposition at the injection point are shown in Figure 12. A maximum deposition of about $10 \mathrm{~cm}$ is reached after 33 days of injection. The sediment is then washed out with an average one-year flood event.

Table 2. Percentage of deposition in each reservoir after 10 hours of injection.

\begin{tabular}{llll}
\hline & $\%$ Deposition & & $\%$ Deposition \\
\cline { 2 - 3 } Reservoir & $\mathrm{Q}=880 \mathrm{~m}^{3} / \mathrm{s}$ & & $\mathrm{Q}=1^{\prime} 250 \mathrm{~m}^{3} / \mathrm{s}$ \\
\hline RADAG & 32 & 13 \\
Laufenburg & 8 & 4 \\
Säckingen & 4 & 10 \\
Ryburg & 8 & 1 \\
Rheinfelden & 1 & 1 \\
Augst-Wyhlen & 2 & 2 \\
Birsfelden & 3 & \\
\hline
\end{tabular}




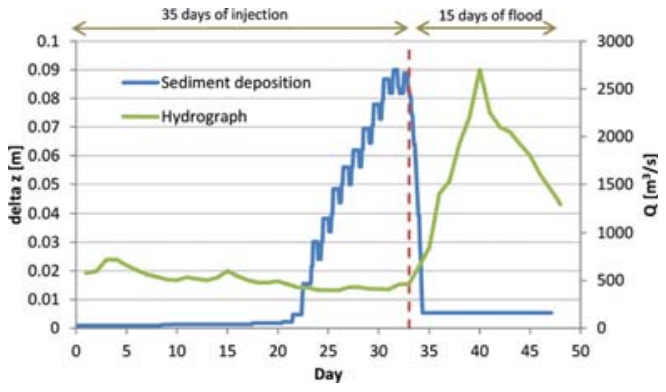

Figure 12. Deposition at the injection point after 33 days (10 hours of injection and 14 hours of pause every day) during a dry year following by a one year flood event.

\section{CONCLUSIONS}

The deposited material behind Klingnau dam, which mostly consists of clay and silt, will be excavated and re-injected to the Rhine River. To investigate suspended load transport in the Rhine River one and Two-dimensional models are used. The obtained results a good accordance between these two models.

For a range of examined discharges of 880 to $1250 \mathrm{~m}^{3} / \mathrm{s}$ about 45 to $60 \%$ of injected material is deposited in the 7 reservoirs along Rhine River. About $30 \%$ of the position occurs in the most upstream reservoir, RADAG. However, even if the injection is performed at very low discharges in the Rhine, i.e. a typical dry year, a subsequent annual flood event is capable to wash out practically all the deposited material.

\section{REFERENCES}

García, M., and G. Parker, 1991, Entrainment of bed sediment into suspension, Journal of Hydraulic Engineering, 117(4): 414-435.

McLean, S.R., 1991, Depth-integrated suspended-load calculations, Journal of Hydraulic Engineering, 117(11): 1440-1458.

McLean, S.R., 1992, On the calculation of suspended load for non-cohesive sediments, 1992, Journal of Geophysical Research, 97(C4), 1-14.

Metron report, 2010, Stausee Klingnau; Reaktivierung Seitenarm-Bauprojekt (unpublished report).

Metron report, 2013, Stausee Klingnau. (unpublished report).

Toffaleti, F.B., 1968. Technical Report No. 5-A Procedure for Computation of Total River Sand Discharge and Detailed Distribution, Bed to Surface. Committee on Channel Stabilization, U.S. Army Corps of Engineers.

USACE, 2013. HEC-RAS Hydrologic Engineering Centers River Analysis System, reference and users manuals.

Van Rijn, L.C. 1984. Sediment transport, Part II: suspended load transport. Journal of Hydraulic Engineering. 110(10): 1431-1456.

VAW-ETH Zürich, 2013. BASEMENT reference and user manuals, http://www.basement.ethz.ch/. 